\title{
History of intraperitoneal platinum drug delivery for ovarian cancer and its future applications
}

\author{
Franco Muggia', Andrea Bonetti ${ }^{2}$ \\ 1Department of Medical Oncology, New York University Langone Health, New York, NY 10016, USA. \\ 2Department of Medical Oncology, Mater Salutis Hospital, AULSS 9 of the Veneto Region, Legnago (VR) 37121, Italy.
}

Correspondence to: Dr. Franco Muggia, Department of Medical Oncology, New York University Langone Health, Perlmutter Cancer Center at NYU Langone Medical Center, 160 East 34th street, New York, NY 10016, USA.

E-mail: Franco.Muggia@nyulangone.org

How to cite this article: Muggia F, Bonetti A. History of intraperitoneal platinum drug delivery for ovarian cancer and its future applications. Cancer Drug Resist 2021;4:453-62. http://dx.doi.org/10.20517/cdr.2020.116

\author{
Received: 24 Dec 2020 First Decision: 12 Jan 2021 Revised: 5 Feb 2021 Accepted: 20 Feb 2021 Available online: 19 Jun 2021 \\ Academic Editor: Godefridus J. Peters Copy Editor: Yue-Yue Zhang Production Editor: Yue-Yue Zhang
}

\begin{abstract}
Intraperitoneal (IP) delivery of cisplatin was developed in the 1970s based on a strong pharmacologic rationale and rodent models. Its advantage over intravenous (IV) administration was supported initially by observational studies in treating recurrent ovarian cancer and eventually by better outcomes from IP vs. IV cisplatin in randomized studies in patients undergoing optimal surgical debulking at diagnosis. In the past two decades, with the introduction of novel anticancer interventions (such as taxanes, bevacizumab, inhibitors of DNA repair, and immune check point inhibitors), advantages of IP drug delivery are less clear and concerns are raised on cisplatin's therapeutic index. The discovery of BRCA genes and their key role in DNA repair, on the other hand, have strengthened the rationale for IP drug delivery: high grade serous cancers arising in the Mullerian epithelium in association with hereditary or somatic BRCA function inactivation are linked to peritoneal spread of cells that - while initially sensitive - are prone to emergence of platinum resistance. Therefore, selection of patients based on genomic features and focusing on the better tolerated IP carboplatin are ongoing. Recent examples of leveraging the peritoneal route include (1) targeting the cell membrane copper transport receptor - that is shared by platinums - by the combination of the proteasome inhibitor bortezomib and IP carboplatin; and (2) enhancing IP 5-fluoro-2-deoxyuridine cytotoxicity when coupled with PARP inhibition.
\end{abstract}

Keywords: Platinum drugs, intraperitoneal administration, epithelial ovarian carcinoma 


\section{INTRODUCTION}

Platinum resistance is the central issue in the treatment of most ovarian cancers. The development of cisplatin as an anticancer agent was reviewed by us at the 50th anniversary of the discovery of its potential anticancer properties ${ }^{[1]}$. Early in its clinical development, cisplatin showed unprecedented activity against ovarian cancer - a disease that is usually diagnosed at advanced stages, with surgery most often playing an ancillary role in its treatment. Although cisplatin - and the subsequent platinum analogs introduced in order to attenuate some of its toxicities - can be relied to induce tumor regressions in up to $90 \%$ of late presentations, most women's cancers eventually recur. In its most common subtype, the high-grade serous adenocarcinoma, tumor progression occurs predominantly in the peritoneal cavity a few months to years after treatment with surgery and the initial "platinum-doublet". These regimens usually combine a platinum with paclitaxel, with the latter occasionally replaced by other drugs with similar anti-tumor activity as single agent taxanes. Recurrences are commonly classified as "platinum resistant" or "platinum sensitive" based on the timing of when these relapses are documented: if after completing 5 or 6 cycles of platinumcontaining regimen, the designation "platinum resistant" is given ${ }^{[2,3]}$. This arbitrary "operational definition" recognizes that cancer reappearance within 6 months of completing 5-6 platinum cycles usually yields at best short-lasting benefits when treated again with a platinum as single agent or as part of a doublet. In fact, even "platinum sensitive" recurrences may reflect some degree of platinum resistance, as suggested by retrospective analysis of 176 women receiving two or more platinum-based regimens for recurrent ovarian cancer, with "the length of a prior response (to the preceding regimen) highly predictive of the upper limit of the duration of response achieved to a subsequent platinum program" ${ }^{\text {"[4] }}$.

Future investigations need to probe deeper into these definitions and how to deal with consolidation drugs applied after completion of first-line treatment cycles. Insights resulting from the cloning of BRCA genes $^{[5,6]}$, their role in homologous recombination ${ }^{[7,8]}$, the sub-classifications of ovarian cancer based on pathology and genomic characteristics ${ }^{[9]}$, and treatment strategies supplementing chemotherapy are in full development. These advances have further emphasized why optimal utilization of the platinum drugs coupled with knowledge of homologous recombination deficiency (HRD) is central to the treatment of the most common subset of ovarian cancer (also including those serous cancers diagnosed as arising in Fallopian tubes or as primary peritoneal cancers). Typically, such cancers are initially not only highly "platinum sensitive", presumably from germline or somatic deleterious BRCA mutations with HRD, but also characterized by their early peritoneal dissemination leading to peritoneal surface implants. These features, bolstered by clinical experience to be cited in this overview suggest a possible role for intraperitoneal (IP) therapy in controlling these molecular subtypes. After reviewing the historical background for cisplatin administration, we shall comment on the possible integration of IP drug administration in strategies designed to minimize the emergence of platinum resistance. As trialists persuaded by improved IP therapy outcomes ${ }^{[10]}$ - in spite of some justified skepticism ${ }^{[11]}$ - we shall focus on how optimizing platinum pharmacodynamics in selected patients manifesting early spread is the appropriate target for IP platinum administration.

\section{INTRAPERITONEAL THERAPY: FROM HISTORICAL ORIGINS TO PRESENT TRIALS}

In 1964 as a Hematology fellow at Columbia's Francis Delafield Cancer Hospital (a remarkable 1950s development of the Municipal Hospital system of New York led by its Health Commissioner Ray Trussel), FM recalls treating ovarian cancer patients suffering with massive ascites by injecting ThioTepa directly into their distended abdomens, sometimes repeatedly. Severe thrombocytopenia was dose-limiting, and any improvements observed were short-lived. Such treatment interventions were promptly discarded but remissions after oral melphalan or cyclophosphamide ${ }^{[12-14]}$ led to routine use of these drugs as systemic monotherapy. Cyclophosphamide's "platelet-sparing" effects led to testing it in drug combinations that eventually claimed to improve median times to progression by a few months over the non-specific DNA damaging alkylating agents ${ }^{[15]}$. At the unusual early stages of ovarian cancer, IP radioactive colloidal 
chromic phosphate $\mathrm{P} 32$ was tested vs. melphalan as consolidation in the absence of residual disease after surgery; subsequently, in a randomized trial vs. systemic cisplatin + cyclophosphamide with a nonsignificant advantage in survival for the latter (GOG95) ${ }^{[16]}$.

By the 1970s, the IP route for drug administration had become the focus of pharmacologic and clinical studies at the National Cancer Institute (NCI), National Institutes of Health (NIH). With Vincent T DeVita Jr, assuming the Directorship of the Division of Cancer Treatment in 1974 to succeed C Gordon Zubrod - who in 1954 was recruited to run the Chemotherapy Program of NCI emphasizing anticancer drug development for hematologic malignancies - its Medicine Branch turned its attention to curative strategies for breast and ovarian cancers. Laparoscopic staging and drug combinations were the initial focus of ovarian cancer clinical protocols. Out of these studies, led by Robert C Young established benefits from the regimen HexaCAF (hexamethylmelamine, cyclophosphamide, methotrexate/Amethopterin and 5 -fluorouracil, soon to be eclipsed by the emergence of cisplatin. Its chemical structure was identified by Rosenberg's laboratory observations at Michigan State and thereafter its development relied on the NCI for preclinical and clinical development ${ }^{[1,17]}$. Medicine Branch trainees (e.g, Robert Ozols, William McGuire, Charles Myers, and James Speyer) became involved in this area of therapeutics and the first two started extensive interactions with extramural gynecologists who since 1970 with NCI support began clinical trials under the umbrella of the Gynecologic Oncology Group (GOG)-paralleling actions created under NCI Clinical Cooperative Groups seeking to integrate clinical drug development with surgery and radiation. GOG became the centerpiece for the future testing of cisplatin and paclitaxel - the most successful anticancer drugs emerging from studies fully coordinated by the NCI.

The pharmacologic basis for IP drug delivery was developed by Robert L Dedrick at the $\mathrm{NIH}^{[18]}$, and soon thereafter a number of phase I/II and pharmacokinetics studies with methotrexate, 5-fluoruracil, and the novel antitumor antibiotic doxorubicin were launched at the Medicine and Surgery Branches under DeVita's prompting ${ }^{[19-21]}$. Initially, the clinical focus was on drug peritoneal/plasma concentration ratios that were tolerable, but drug diffusivity (penetrance) into tissues and intrinsic tumor sensitivity to a drug was later emphasized as being most relevant to eventual clinical results ${ }^{[22]}$. In fact, Stephen Howell at University of California, San Diego, initiated IP cisplatin studies after the 1979 approval for systemic treatment of ovarian cancer, and reported the most noteworthy clinical results ${ }^{[23]}$. These were compelling enough for Baltimore NCI unit-trained David Alberts in 1985 to a phase III study of cisplatin IP vs. IV (+ IV cyclophosphamide in both arms) within the Ovarian Committee of the Southwest Oncology Group (SWOG). This study completed its lagging accrual with GOG participation (GOG104): its results presented at the American Society of Clinical Oncology plenary session and published in 1996 fostered enthusiasm for further exploration of IP cisplatin ${ }^{[24]}$. Accordingly, it was followed by GOG114 $4^{[25]}$ : this study adopted the new standard IV cisplatin $+24 \mathrm{~h} \mathrm{IV} \mathrm{paclitaxel} \mathrm{as} \mathrm{a} \mathrm{comparator} \mathrm{to} \mathrm{the} \mathrm{IP} \mathrm{cisplatin} \mathrm{arm.} \mathrm{However,}$ this experimental IP arm was modified to be preceded by IV carboplatin AUC $9 \times 2$ cycles as "chemical debulking" before IP cisplatin $+24 \mathrm{~h}$ IV paclitaxel; this resulted in excessive hematologic toxicity. Therefore, even with an improved overall median survival, because of its greater toxicity it could not be "recommend for routine use". Such a conclusion led to the third GOG IV vs. IP comparison in GOG $172^{[26]}$ that included yet another major change in the experimental IP regimen, - now adding a day 8 IP paclitaxel to the IP cisplatin. The median survival results exceeding 5 years first disclosed at the GOG meeting were striking for the IP arm, even though associated with considerably more toxicity and lesser completion rates. An NCI Clinical Announcement followed in January 2006 urging IP treatments was provided for optimally cytoreduced women with stage III ovarian cancer. With each of the IP arms differing among the 3 GOG studies and problematic toxicities blunted adoption of IP regimens outside the US. The late Martin Gore articulated the European position over several years with insightful comments: e.g, "even if IP superiority is confirmed by a subsequent trial, tell me how I should use it" ${ }^{\text {"27] }}$, and after the brilliant results of GOG172 ${ }^{[26]}$, his overall critique was "Lack of robustness of the data lies in the design of the main IP trials, not their 
conduct or analysis". Introduction of IP paclitaxel in GOG172, in particular, was problematic for testing the original hypothesis of IP $v$ s. IV cisplatin and it raised new local and systemic toxicity issues (especially neurotoxicity). Additionally, critics of IP approaches objected that the comparator in the IV arm was cisplatin and not the by now current standard IV carboplatin (based on Ozols' non-inferiority trial GOG158 comparing the two platinums, both with IV paclitaxel, that favored carboplatin) ${ }^{[28]}$.

In the GOG172 IP regimen the long-lasting neurotoxicity and other concerns associated with cisplatin for up to 6 cycles at the excessive doses (for women) of $100 \mathrm{mg} / \mathrm{m}^{2}$ given on day 2 (coupled with IV paclitaxel on day 1) were further compounded by an additional paclitaxel IP on day 8. Therefore, the GOG embarked on piloting several modified IP regimens with cisplatin at $75 \mathrm{mg} / \mathrm{m}^{2}$ (but still retaining the IP paclitaxel on day 8). After 3 years of IP pilot studies, other concepts gained traction (weekly-dose dense-paclitaxel based on Japanese GOG, and bevacizumab impact in GOG and ICON groups). These innovations led to GOG252: a 3-way comparison enrolling 1,560 women randomized to (1) a reduced cisplatin dose-modified GOG172 IP regimen; (2) $80 \mathrm{mg} / \mathrm{m}^{2}$ IV paclitaxel $\mathrm{d} 1,8,15$ (acquired from the Japanese GOG study) given together with IP carboplatin at target AUC dosing of 6 or 3) the same two drugs and respective doses with both given IV. Bevacizumab every 3 weeks was added to each $\operatorname{arm}^{[29]}$. The final analysis of this study was published in 2019 - three years after initial analysis of progression free survival (PFS) had been presented showing no significant differences between the $3 \mathrm{arms}$ but with quality of life less affected in the IP or IV carboplatin arms. As anticipated, the mature overall survival (OS) analysis was similar in all three arms, exceeding 6 years in all three regimens. These results were definitive enough to reverse any impact on clinical practice including IP cisplatin administration that the 2006 Clinical Announcement had recommended. The brisk enrollment into this trial, however, reflects the ease gynecologic oncologists have adopted IP interventions, not impeding entry into such administration into studies. The overall lack of advantage in outcome, however, has essentially nullified IP interventions as a standard option relative to IV regimens that uniformly rely on carboplatin doublets. Whether differences were blurred by introducing weekly paclitaxel in two of the arms (and also on d8 IP in the modified GOG172 regimen) and by bevacizumab improving PFS in all three arms, or by diminished efficacy of the lower IP cisplatin dose $\left(75 \mathrm{mg} / \mathrm{m}^{2}\right.$ per cycle rather $\left.100 \mathrm{~g} / \mathrm{m}^{2}\right)$ is a currently unanswerable question. While trialists consider future directions of IP interventions, the Dutch group randomized patients to hyperthermic IP chemotherapy (HIPEC) utilizing cisplatin $\times 1$ HIPEC following 3 cycles of carboplatin/paclitaxel and surgical cytoreduction $v s$. the same surgical intervention without HIPEC. Both arms went on to receive additional 3 cycles of carboplatin/paclitaxel. This study provided a statistically significant survival advantage for the HIPEC $\operatorname{arm}^{[30]}$. HIPEC has been applied at different time points of treatment of advanced epithelial ovarian carcinoma, namely up-front, interval, and recurrent setting ${ }^{[31]}$. However, the use of HIPEC following neoadjuvant chemotherapy (NACT) at the time of interval debulking surgery is the most promising since it is based on a higher level of evidence ${ }^{[30]}$ and perhaps should be able to reverse the platinum-resistance induced by neo-adjuvant chemotherapy ${ }^{[32]}$. Furthermore, the observation that hyperthermia delayed the repair of DNA damage induced by cisplatin or doxorubicin acting upstream of different repair pathways to block histone polyADP-ribosylation (PARylation), as efficiently as pharmacologic inhibitors of PARP (PARPi), producing comparable delay in DNA repair, induction of double-strand breaks, and cell cytotoxicity after chemotherapy could suggest a potential synergistic effect of HIPEC and PARP1 inhibitor ${ }^{[33]}$, to be evaluated in clinical trials. In the post-NACT and optimal surgical debulking setting the Gynecologic Cancer Intergroup performed a two-stage adaptively designed randomized phase II study of intraperitoneal $v s$. intravenous chemotherapy ${ }^{[34]}$. Patients were randomized to one of 3 arms: (1) i.v. carboplatin/paclitaxel control arm; (2) i.p. cisplatin plus i.v./i.p. paclitaxel; or (3) i.p. carboplatin plus i.v./i.p. paclitaxel with the primary endpoint being 9-month progressive disease (PD9) rate before going on to an anticipated two-arm phase III comparison of the intravenous standard vs. one of the intraperitoneal arms. The IP cisplatin arm did not progress beyond the first stage of the study after failing to meet the PD9 pre-set superiority rule the final analysis compared i.v. carboplatin/paclitaxel $(n=101)$ while i.p carboplatin, i.v./i.p. 
paclitaxel $(n=102)$ did show a lower PD9 rate compared with the i.v. carboplatin/paclitaxel control arm: 24.5\% (95\%CI: $16.2 \%-32.9 \%$ ) vs. 38.6\% (95\%CI: $29.1 \%-48.1 \%)(P=0.065)$. Regrettably, the planned phase III trial was aborted due to insufficient funding.

\section{IP PLATINUM-BASED THERAPY: REFINING THE QUESTIONS}

Most positive signals from IP drug administration have been obtained in epithelial ovarian cancer with high-grade serous cancers and early peritoneal spread - many originate in the fimbria of the Fallopian tubes ${ }^{[35-37]}$. Early NCI studies on IP therapy concentrated on ovarian cancer because one could attain a pharmacologic advantage with a number of chemotherapy agents. Subsequently, the IP route would be deemed ideal following "early diagnosis" or "optimally debulked" in a disease initially confined to the peritoneal cavity -for example, we have since learned from BRCA mutation-related serous cancers discovered incidentally at risk-reducing salpingo-oophorectomies in hereditary mutation carriers. The studies conducted by UCSD and the GOG reviewed in detail had signaled improvements in outcome for IP cisplatin administration and reinforced by the initial 3 GOG studies utilizing cisplatin at $100 \mathrm{mg} / \mathrm{m}^{2}$ per cycle, but varied in some aspects of patient eligibility (tumor residual) as well as accompanying added treatments in the IP cisplatin arm. In the last GOG252, all differences became blurred with superior overall outcome results suggesting a contribution of bevacizumab to IV and both IP arms. Rather than discarding the prior undoubtedly positive signals following IP drug administration, we suggest that one should consider the following steps: (1) refining eligibility to concentrate on HRD deficient disease and where most favorable low-volume disease distribution might be expected; (2) testing out other potentiators of IP platinums; and (3) reinforcing potential practical advantages of IP administered drugs.

\section{IP ROUTE: PATIENT SELECTION}

As a reference point, the NCI The Cancer Genome Atlas on ovarian cancer provided a comprehensive analysis of genomic alteration in high grade serous cancers ${ }^{[9]}$. If an advantage from IP administration over IV is going to emerge, the patient selection should initially be confined to those with demonstrable genetic mutations of BRCA and/or other germline or somatic alterations resulting in HRD. Retrospective studies have shown an improved prognosis, higher response rates to platinum-containing regimens, and longer treatment-free intervals between relapses in patients with BRCA 1 and BRCA 2 (BRCA1/2)-mutated ovarian cancer compared with patients who are not carriers of this mutation ${ }^{[38]}$. Regarding the role of IP therapy in BRCA-mutated ovarian cancer, an ancillary study of a subset of GOG 172 patients revealed that those with reduced $B R C A 1$ expression greatly benefitted from IP rather than IV chemotherapy: in tumors with aberrant $B R C A 1$ expression the median OS was 84 months $v s .47$ months in the IP vs. IV group, respectively $(P=0.0002)^{[39]}$. Moreover, in a retrospective study of OS among 62 patients entering in IP platinum doublet phase II trials performed at NYU, a subset of 10 patients later documented to have germline BRCA mutations experienced a very long median survivals $(10+\text { years })^{[40]}$.

Beyond BRCA mutations and other HRD features, patients should be optimally cytoreduced up front and include only stages II or III. Anyone undergoing additional resections of bowel and visceral organs might also need to be excluded. To avoid additional issues not related to IP $v s$. IV comparisons, one should consider using the same platinum agent in IV and IP arms, that is, carboplatin. In this era of pretreatment genomic analysis, one could include additional accompanying biomarker studies of outcome, and detection of early recurrence by ctDNA, as an example. In addition to attempting to confirm an IP $v s$. IV advantage in this selected population, the IP delivery lends itself to potentiating the action of platinums by this route. The next section will describe studies that provided positive leads but unfortunately have not followed up to date, in part because clinical investigations without pharmaceutical industry sponsorship are challenging to get underway more than ever. 
Table 1. Intraperitoneal vs. Intravenous Phase III trials

\begin{tabular}{|c|c|c|c|c|c|c|c|}
\hline Study & $\begin{array}{c}\text { No. of } \\
\text { patients }\end{array}$ & $\begin{array}{c}\text { IP vS. } \\
\text { Control }\end{array}$ & Chemotherapy & $\begin{array}{l}\text { Median PFS } \\
\text { (months) }\end{array}$ & $\begin{array}{c}P \\
\text { value }\end{array}$ & $\begin{array}{l}\text { Median OS } \\
\text { (months) }\end{array}$ & $\begin{array}{c}P \\
\text { value }\end{array}$ \\
\hline Zylberberg et al. $^{[48]} 1986$ & 20 & $\begin{array}{l}\text { IV/IP } \\
\text { Control }\end{array}$ & $\begin{array}{l}\text { Arm 1: IV adriamycin } 35 \mathrm{mg} \times 2+\text { fluorouracil } 750 \mathrm{mg} \times 2 \text { + bleomycin } 15 \mathrm{mg}+\text { cisplatin } \\
100 \mathrm{mg}+\text { vincaleucoblastine } \\
10 \mathrm{mg}+\text { ifosfamide } 1 \mathrm{~g} \times 2 \\
\text { Arm 2: IV adriamycin } 20 \mathrm{mg} \times 2+\text { fluorouracil } 500 \mathrm{mg} \times 2+\text { cisplatin } 50 \mathrm{mg}+ \\
\text { vincaleucoblastine } 10 \mathrm{mg}+ \\
\text { ifosfamide } 1 \mathrm{~g} \times 2+\mathrm{IP} \text { bleomycin } 15 \mathrm{mg}+\text { cisplatin } 50 \mathrm{mg}+\text { fluorouracil } 500 \mathrm{mg}+ \\
\text { adriamycin } 30 \mathrm{mg}\end{array}$ & NR & & NR & \\
\hline Kirmani et al. ${ }^{[49]} 1994$ & $\begin{array}{l}29 \\
33\end{array}$ & $\begin{array}{l}\text { IP } \\
\text { Control }\end{array}$ & $\begin{array}{l}\text { IP Cisplatin } 200 \mathrm{mg} / \mathrm{m}^{2}+\text { IP Etoposide } 350 \mathrm{mg} / \mathrm{m}^{2} \text { every } 28 \text { days for } 6 \text { cycles } \\
\text { IV cisplatin } 100 \mathrm{mg} / \mathrm{m}^{2}+\text { IV cyclophosphamide } 600 \mathrm{mg} / \mathrm{m}^{2} \text { every } 21 \text { days for six cycles }\end{array}$ & $\begin{array}{l}14 \\
12\end{array}$ & 0.46 & $\begin{array}{l}32 \\
36\end{array}$ & 0.45 \\
\hline GOG $1041996^{[24]}$ & $\begin{array}{l}267 \\
279\end{array}$ & IP Control & $\begin{array}{l}\text { IV cyclophosphamide } 600 \mathrm{mg} / \mathrm{m}^{2}+\text { IP cisplatin } 100 \mathrm{mg} / \mathrm{m}^{2} \\
\text { IV cyclophosphamide } 600 \mathrm{mg} / \mathrm{m}^{2}+\text { IV cisplatin } 100 \mathrm{mg} / \mathrm{m}^{2}\end{array}$ & $\begin{array}{l}\text { NR } \\
\text { NR }\end{array}$ & & $\begin{array}{l}49 \\
41\end{array}$ & 0.02 \\
\hline Polyzos et al. ${ }^{[50]} 1999$ & 44 & Control & $\begin{array}{l}\text { IP Carboplatin } 350 \mathrm{mg} / \mathrm{m}^{2}+\text { IV cyclophosphamide } 600 \mathrm{mg} / \mathrm{m}^{2} \text { every three weeks for } 6 \\
\text { cycles } \\
\text { IV Carboplatin } 350 \mathrm{mg} / \mathrm{m}^{2}+\text { IV cyclophosphamide } 600 \mathrm{mg} / \mathrm{m}^{2} \text { every three weeks for } \\
6 \text { cycles }\end{array}$ & $\begin{array}{l}18 \\
19\end{array}$ & NS & 26 & NS \\
\hline Gadducci et al. ${ }^{[51]} 2000$ & 113 & $\begin{array}{l}\text { IP } \\
\text { Control }\end{array}$ & $\begin{array}{l}\text { IP cisplatin } 50 \mathrm{mg} / \mathrm{m}^{2}+\text { IV doxorubicin } 60 \mathrm{mg} / \mathrm{m}^{2}+\text { IV cyclophosphamide } 600 \mathrm{mg} / \mathrm{m}^{2} \\
\text { every } 4 \text { weeks for } 6 \text { cycles } \\
\text { IV cisplatin } 50 \mathrm{mg} / \mathrm{m}^{2}+\mathrm{IV} \text { doxorubicin } 60 \mathrm{mg} / \mathrm{m}^{2}+\mathrm{IV} \text { cyclophosphamide } 600 \mathrm{mg} / \mathrm{m}^{2} \\
\text { every } 4 \text { weeks for } 6 \text { cycles }\end{array}$ & $\begin{array}{l}42 \\
25\end{array}$ & 0.13 & $\begin{array}{l}67 \\
51\end{array}$ & 0.14 \\
\hline Yen et al. ${ }^{[52]} 2001$ & $\begin{array}{l}55 \\
63\end{array}$ & $\begin{array}{l}\text { IP } \\
\text { Control }\end{array}$ & $\begin{array}{l}\text { IP cisplatin } 100 \mathrm{mg} / \mathrm{m}^{2}+\text { IV cyclophosphamide } 500 \mathrm{mg} / \mathrm{m}^{2} \text { every three weeks for } 6 \\
\text { cycles } \\
\text { IP cisplatin } 50 \mathrm{mg} / \mathrm{m}^{2}+\text { IV cyclophosphamide } 500 \mathrm{mg} / \mathrm{m}^{2} \\
\text { every three weeks for } 6 \text { cycles }\end{array}$ & NR & & $\begin{array}{l}43 \\
48\end{array}$ & 0.47 \\
\hline GOG $1142001^{[25]}$ & $\begin{array}{l}235 \\
227\end{array}$ & $\begin{array}{l}\text { IP } \\
\text { Control }\end{array}$ & $\begin{array}{l}\text { IV carboplatin AUC } 9 \text { every } 28 \text { days for two cycles, followed } 28 \text { days later by IV } \\
\left.\text { paclitaxel } 135 \mathrm{mg} / \mathrm{m}^{2} \text { over } 24 \mathrm{~h} \text { (day } 1\right)+ \text { IP cisplatin } 100 \mathrm{mg} / \mathrm{m}^{2} \text { (day 2) } \\
\left.\text { IV paclitaxel } 135 \mathrm{mg} / \mathrm{m}^{2} \text { over } 24 \mathrm{~h} \text { (day } 1\right)+ \text { IV cisplatin } 75 \mathrm{mg} / \mathrm{m} 2 \text { (day } 2 \text { ) }\end{array}$ & $\begin{array}{l}28 \\
22\end{array}$ & 0.01 & $\begin{array}{l}63 \\
52\end{array}$ & 0.05 \\
\hline GOG $1722006^{[26]}$ & $\begin{array}{l}205 \\
210\end{array}$ & $\begin{array}{l}\text { IP } \\
\text { Control }\end{array}$ & $\begin{array}{l}\left.\left.\text { IV paclitaxel } 135 \mathrm{mg} / \mathrm{m}^{2} \text { over } 24 \mathrm{~h} \text { (day } 1\right)+ \text { IP cisplatin } 100 \mathrm{mg} / \mathrm{m}^{2} \text { (day } 2\right)+ \text { IP } \\
\text { paclitaxel } 60 \mathrm{mg} / \mathrm{m}^{2} \text { (day } 8 \text { ) } \\
\left.\left.\text { IV paclitaxel } 135 \mathrm{mg} / \mathrm{m}^{2} \text { over } 24 \mathrm{~h} \text { (day } 1\right)+ \text { IV cisplatin } 75 \mathrm{mg} / \mathrm{m}^{2} \text { (day } 2\right)\end{array}$ & $\begin{array}{l}24 \\
18\end{array}$ & 0.05 & $\begin{array}{l}65.6 \\
49.7\end{array}$ & 0.03 \\
\hline GOG $2522019^{[29]}$ & $\begin{array}{l}518 \\
521 \\
521\end{array}$ & $\begin{array}{l}\text { IP carbo } \\
\text { IP cis } \\
\text { Control }\end{array}$ & $\begin{array}{l}\text { IV paclitaxel } 80 \mathrm{mg} / \mathrm{m} 2 \text { weekly + IP carboplatin AUC } 6 \text { + bevacizumab } 15 \mathrm{mg} / \mathrm{kg} \text { every } \\
3 \text { weeks } \\
\text { IV paclitaxel } 135 \mathrm{mg} / \mathrm{m}^{2} \text { over } 3 \mathrm{~h} \text { day } 1+\text { IP cisplatin } 75 \mathrm{mg} / \mathrm{m}^{2} \text { day } 2+\text { IP paclitaxel } 60 \\
\mathrm{mg} / \mathrm{m}^{2} \text { day } 8+\text { bevacizumab } 15 \mathrm{mg} / \mathrm{kg} \text { every } 3 \text { weeks } \\
\text { IV paclitaxel } 80 \mathrm{mg} / \mathrm{m}^{2} \text { weekly + IV carboplatin AUC } 6 \text { + bevacizumab } 15 \mathrm{mg} / \mathrm{kg} \text { every } \\
3 \text { weeks } \\
\text { (all arms bevacizumab from cycles } 2-22 \text { ) }\end{array}$ & $\begin{array}{l}27.4 \\
26.2 \\
24.9\end{array}$ & N.S. & $\begin{array}{l}78.9 \\
72.9 \\
5.5\end{array}$ & NS \\
\hline
\end{tabular}

${ }^{\star}$ This is the earliest RCT on IP chemotherapy for the initial management of epithelial ovarian cancer. The Authors described a statistically significant increase in the number of women alive and free of disease in the IP group $(P<0.05)$ but no further statistics were provided ${ }^{[47]}$.

\section{IP ROUTE: ADDRESSING NEW HYPOTHESES IN OVERCOMING PLATINUM RESISTANCE}

\section{USING IP THERAPY}

Data from Howell's laboratory targeting the cell membrane copper transport receptor (CTR) shared by platinums suggested that cisplatin resistance was overcome by the combination of the proteasome inhibitor bortezomib and cisplatin ${ }^{[41,42]}$. The GOG set out to prove this hypothesis by conducting a clinical trial in patients with peritoneal recurrence mimicking Howell's preclinical data. In the study by Jandial et al. ${ }^{[43]}, 33$ heavily pretreated women meeting eligibility criteria were enrolled in the phase I/pharmacokinetic study to evaluate the safety of IP carboplatin AUC 5 and bortezomib $0.5 \mathrm{mg} / \mathrm{m}^{2}$. Twenty-one of these patients had measurable disease with one complete and 3 partial responses (overall response rate 19\%) were noted. With the clinical experience of IP placement over several decades the leads from this phase I study should be pursued among other hypotheses that need to be tested about overcoming resistance, especially since this study demonstrated clinical benefit with a satisfactory therapeutic index. Moreover, it exemplifies a path of going from animal models into human study that has not been exploited.

Series of trials utilizing the IP route in patients with ovarian cancer recurrences to assess potential drug activity alone and in combination with platinums were carried out by the GOG102 in the early 1990 s (terminated when joining the phase III SWOG study as GOG104). We had studied IP fluoropyrimidines, and specifically 5 -fluoro-2-deoxyuridine (FUDR) as single agent ${ }^{[44]}$ and this arm was one of the two selected of a SWOG randomized phase 2 study ${ }^{[4]}$. In this trial its progression free survival vastly exceeded that of IP mitoxantrone that had been selected based on anecdotal reports of activity. Subsequently, we went on to combine FUDR with platinums for further development as a promising combination but it was displaced by the emerging interest of IP paclitaxel (that was later included in GOG172 and in the modified arm of GOG252). While further development stalled, Scott Kaufmann's laboratory studies in Mayo Clinic had established that IP FUDR but not 5-fluorouracil potentiated the effect of PARP inhibitors ${ }^{[46,47]}$. This led to an institutional Phase I clinical study of IP FUDR coupled with oral veliparib (A. Wahner Hendrickson, unpublished) that completed accrual in 2019. These are examples of how leveraging PARP inhibition and 
Table 2. Advantages and disadvantages of intraperitoneal drug administration

\begin{tabular}{ll}
\hline Advantages & \multicolumn{1}{c}{ Disadvantages } \\
\hline$\uparrow \uparrow$ Drug concentration at peritoneal disease sites & May not apply to sizable tumors \& areas of poor exposure \\
Mostly "active" cisplatin after IP delivery in NS & Ongoing cisplatin inactivation after IV delivery \\
FUdR mostly intact at peritoneal disease sites & Not feasible IV: FUdR IV is hydrolyzed to 5-fluorouracil (5FU) \& no \\
& synergy with PARPi \\
Synergy of IP FUdR with oral PARP inhibitors & FUDR requires port to synergize PARPi \\
IP Port may facilitate cytological sampling & Surgery to insert access port; malfunction 10\% \\
IP drugs enter circulation: reach tumors also by capillary flow, but & Drug exposure of tumors beyond surface could be less than after IV \\
less peak levels (for cisplatin that translates in lesser nephro- and administration & \\
\hline
\end{tabular}
oto-toxicity

NS: Normal saline; FUdR: 5-fluoro-2-deoxyruridine; 5FU: 5-fluoruracil; PARPi: inhibitors of poly (ADP-ribose) polymerase.

IP drug combinations overcome relative resistance to the platinum drugs that may be less achievable by the systemic route. All our experience with peritoneal ports may allow monitoring for ctDNA in peritoneal washings. In fact, in our unpublished experience based on monitoring peritoneal cytology every 6 weeks $\times 4$ after completion of IP treatment does lead to a $10 \%$ early detection of peritoneal recurrences not otherwise detectable by imaging or CA125 increase (FM, personal communication). Removing the port at 6 months was chosen as a compromise of having to deal with the port a few more months after completion of treatment (unless chronically uncomfortable) and detecting a "platinum-resistant" peritoneal relapse that might be appropriate for experimental IP therapies.

\section{OVERVIEW AND FUTURE DIRECTIONS}

Platinum-resistance is a key element of the challenging relapses that follows all approaches to highgrade serous ovarian cancers. We have reviewed how intraperitoneal therapy was developed and its pharmacologic basis led to phase III trials that have provided mostly positive signals, but also associated with increasing toxicities. A summary of published phase III trials comparing IP with IV administrations of platinum-containing regimens, including studies performed before the introduction of taxanes ${ }^{[48-52]}$ is reported in Table 1. The table is built upon the paper published by the Cochrane library ${ }^{[53]}$ and by the Cancer Care Ontario ${ }^{[54]}$. The Cochrane concluded that women receiving primary treatment for ovarian cancer were less likely to die if they received an IP component to chemotherapy (eight studies, 2026 women; $\mathrm{HR}=0.81 ; 95 \% \mathrm{CI}: 0.72$ to 0.90 ) and that there was greater serious toxicity with regard to gastrointestinal effects, pain, fever and infection but less ototoxicity with the IP than the IV route. Table 2 summarizes potential advantages and disadvantages of the IP route as research strategy vis-à-vis the IV (standard) route. Finally, the GOG 252 trial demonstrates IP drug delivery may be integrated into clinical practice with relative ease. Our historical overview provides a background whereby new studies may address key questions in overcoming platinum resistance utilizing the IP route, addressing questions by collaborating with basic and translational scientists.

\section{DECLARATIONS}

\section{Authors' contributions}

Study Concept and design: Muggia F, Bonetti A

Drafting of the manuscript: Muggia F, Bonetti A

Critical revision of the manuscript: Muggia F, Bonetti A

\section{Availability of data and materials}

Not applicable.

\section{Financial support and sponsorship}


None.

\section{Conflicts of interest}

All authors declared that there are no conflicts of interest.

\section{Ethical approval and consent to participate}

Not applicable.

\section{Consent for publication}

Not applicable.

\section{Copyright}

(c) The Author(s) 2021.

\section{REFERENCES}

1. Muggia FM, Bonetti A, Hoeschele JD, Rozencweig M, Howell SB. Platinum antitumor complexes: 50 years since Barnett Rosenberg's discovery. J Clin Oncol 2015;33:4219-26.

2. Markman M, Rothman R, Hakes T, et al. Second-line platinum therapy in patients with ovarian cancer previously treated with cisplatin. $J$ Clin Oncol 1991;9:389-93.

3. Seltzer V, Vogl S, Kaplan B. Recurrent ovarian carcinoma. Retreatment utilizing combination chemotherapy including cisdiamminedichloroplatinum in patients previously responding to this agent. Gynecol Oncol 1985;21:167-76.

4. Markman M, Markman J, Webster K, et al. Duration of response to second-line platinum-based chemotherapy for ovarian cancer: implications for patient management and clinical trial design. J Clin Oncol 2004; 22:3120-25.

5. Miki Y, Swensen J, Shattuck-Eidens D, et al. A strong candidate for the breast and ovarian cancer susceptibility gene BRCA1. Science 1994;266:66-71.

6. Wooster R, Bignell G, Lancaster J, et al. Identification of the breast cancer susceptibility gene BRCA2. Nature 1995;378:789-92.

7. Snouwaert JN, Gowen LC, Latour AM, et al. BRCA1 deficient embryonic stem cells display a decreased homologous recombination frequency and an increased frequency of non-homologous recombination that is corrected by expression of a BRCA1 transgene. Oncogene 1999;18:7900-7.

8. Moynahan ME, Pierce AJ, Jasin M. BRCA2 is required for homology-directed repair of chromosomal breaks. Mol Cell 2001;7:263-72

9. The Cancer Genome Atlas Research Network. Integrated genomic analyses of ovarian carcinoma. Nature 2011;474:609-15

10. Armstrong DK, Walker JL. Role of intraperitoneal therapy in the initial mangement of ovarian cancer. J Clin Oncol 2019;37:2416-19.

11. Vergote I, Harter P, Chiva L. Is there a role for intraperitoneal chemotherapy, including HIPEC, in the management of ovarian cancer? $J$ Clin Oncol 2019;37:2420-23.

12. Brodovsky HS, Bauer M, Horton J, Elson PJ. Comparison of melphalan with cyclophosphamide, methotrexate and 5-fluorouracil in patients with ovarian cancer. Cancer 1984;53:844-52.

13. Beck RE, Boyes DA. Treatment of 126 cases of advanced ovarian carcinoma with cyclophosphamide. Can Med Assoc J 1968;98:539-41

14. Hasan J, Jayson JC. Oral melphalan as a treatment for platinum-resistant ovarian cancer. Br J Cancer 2003;88:1828-30

15. Young RC, Chabner BA, Hubbard SP, et al. Advanced ovarian adenocarcinoma. A prospective clinical trial of melphalan (L-PAM) versus combination chemotherapy. N Engl J Med 1978;299:1261-66.

16. Young RC, Brady MF, Nieberg RE, et al. Adjuvant treatment for early ovarian cancer: a randomized phase III trial of intraperitoneal 32P or cyclophosphamide cisplatin-a gynecologic oncology group study. J Clin Oncol 2003;21:4350-55.

17. Muggia FM, Rozencweig M, Bono VH, Jacobs EM, Jr. Cis-dichlorodiammineplatinum (II): the trail from an inert electrode to a therapeutic solution. Introduction to Proceedings of NCI Conference on cis-platinum and testicular cancer. Cancer Treat Rep 1979;63:1431.

18. Dedrick RL, Myers CE, Bungay PM, De Vita VT. Pharmacokinetic rationale for peritoneal drug administration in the treatment of ovarian cancer. Cancer Treat Rep 1978;62:1-11.

19. Jones RB, Collins JM, Myers CB, at al. High volume intraperitoneal chemotherapy with methotrexate in patients with cancer. Cancer Res 1981;41:55-9.

20. Speyer JL, Sugarbaker PH, Collins JM, Dedrick RL, Klecker RW Jr, Myers CE. Portal levels and hepatic clearance of 5-fluorouracil after intraperitoneal administration in humans. Cancer Res 1981;41,1916-22.

21. Ozols RF, Young RC, Speyer JL, et al. Phase I and pharmacological study of Adriamycin administered intraperitoneally in patients with ovarian cancer. Cancer Res 1982;42:4265-9

22. Dedrick RL, Flessner MF. Pharmacokinetic problems in peritoneal drug administration: tissue penetration and surface exposure. $J$ Natl Cancer Inst 1996;89:480-7.

23. Howell SB, Zimm S, Markman M, et al. Long term survival of advanced refractory ovarian carcinoma patients with small-volume disease treated with intraperitoneal chemotherapy. J Clin Oncol 1987;5:1607-12. 
24. Alberts DS, Liu PY, Hannigan EV, et al. Intraperitoneal cisplatin plus intravenous cyclophosphamide versus intravenous cisplatin plus intravenous cyclophosphamide for stage III ovarian cancer. $N$ Engl J Med 1996;335:1950-5.

25. Markman M, Bundy BN, Alberts DS, et al. Phase III trial of standard-dose intravenous cisplatin plus paclitaxel versus moderately high-dose carboplatin followed by intravenous paclitaxel and intraperitoneal cisplatin in small-volume stage III ovarian carcinoma: an intergroup study of the Gynecologic Oncology Group, Southwestern Oncology Group. J Clin Oncol 2001;19:1001-7.

26. Armstrong DK, Bundy B, Wenzel L, et al. Intraperitoneal cisplatin and paclitaxel in ovarian cancer. N Engl J Med 2006;354:34-43.

27. Gore M, du Bois A, Vergote I. Intraperitoneal chemotherapy in ovarian cancer remains experimental. J Clin Oncol 2006;4528-30.

28. Ozols RF, Bundy BN, Greer BE, et al. Phase III trial of carboplatin and paclitaxel compared with cisplatin and paclitaxel in patients with optimally resected stage III ovarian cancer: a Gynecologic Oncology Group study. J Clin Oncol 2003;21:3194-200.

29. Walker JL, Brady MF, Wenzel L, et al: Randomized trial of intravenous versus intraperitoneal chemotherapy plus bevacizumab in advanced ovarian carcinoma: An NRG Oncology/Gynecologic Oncology Group Study. J Clin Oncol 2019;37:1380-90.

30. van Driel WJ, Koole SN, Sikorska K, et al. Hyperthermic intraperitoneal chemotherapy in ovarian cancer. $N$ Engl J Med 2018;378:23040.

31. Batista TP, ZIbetti Dal Molin G. Can HIPEC be used against platinum-resistance and for inducing sensitivity to PARP inhibitors in ovarian cancer? Cancer Drug Resist 2020;3:666-71.

32. Da Costa AA, Valdares CV, Baiocchi G, et al. Neoadjuvant chemotherapy followed by interval debulking surgery and the risk of platinum resistance in epithelial ovarian cancer. Ann Surg Oncol 2015;22 Suppl 3:S971-8.

33. Schaaf L, Schwab M, Ulmer C, et al. Hyperthermia synergizes with chemotherapy by inhibiting PARP1-dependent DNA replication arrest. Cancer Res 2016;76:2868-75.

34. Provencher DM, Gallagher CJ, Parulekar WR, et al. OV21/PETROC: a randomized Gynecologic Cancer Intergroup phase II study of intraperitoneal versus intravenous chemotherapy following neoadjuvant chemotherapy and optimal debulking surgery in epithelial ovarian cancer. Ann Oncol 2018;29:431-38.

35. Colgan TJ, Murphy J, Cole DE, Narod S, Rosen B. Occult carcinoma in prophylactic oophorectomy specimens: prevalence and association with BRCA germline mutation status. Am J Surg Pathol 2001;25:1283-89.

36. Piek JM, van Diest PJ, Zweemer RP, et al. Dysplastic changes in prophylactically removed fallopian tubes of women predisposed to developing ovarian cancer. J Pathol 2001;195:451-6.

37. Labidi-Galy SI, Papp E, Hallberg D, et al. High grade serous ovarian carcinomas originate in the fallopian tube. Nat Commun 2017;8:1093.

38. Tan DSP, Kaye S. Chemotherapy for patients with BRCA1 and BRCA2-mutated ovarian cancer: same or different? Am Soc Clin Oncol Educ Book 2015;35:114-21.

39. Lesnock JL, Darcy KM, Tian C, et al. BRCA1 expression and improved survival in ovarian cancer patients treated with intraperitoneal cisplatin and paclitaxel: a Gynecologic Oncology Group Study. Br J Cancer 2013;108:1231-37.

40. Kwa M, Edwards S, Downey A, et al. Ovarian cancer in BRCA mutation carriers: improved outcome after intraperitoneal chemotherapy. Ann Surg Oncol 2014;21:1468-73.

41. Howell SB, Safaei R, Larson CA, Sailor JM. Copper transporters and the cellular pharmacology of the platinum-containing cancer drugs. Mol Pharmacol 2010;77:887-94.

42. Jandial DD, Farshchi-Heydari S, Larson CA, Elliott GI, Wrasidlo WJ, Howell SB. Enhanced delivery of cisplatin to intraperitoneal ovarian carcinomas mediated by the effects of bortezomib on the human copper transporter 1. Clin Cancer Res 2009;15:553-60.

43. Jandial DA, Brady WE, Howell SB, et al A phase I pharmacokinetic study of intraperitoneal bortezomib and carboplatin in patients with persistent or recurrent ovarian cancer: An NRG Oncology/Gynecologic Oncology Group study. Gynecol Oncol 2017;145:236-42.

44. Muggia FM, Jeffers S, Muderspach L, et al. Phase I/II study of intraperitoneal floxuridine and platinums (cisplatin and/or carboplatin). Gynecol Oncol 1997;66:290-94.

45. Muggia FM, Liu PY, Alberts DS, et al. Intraperitoneal mitoxantrone or floxuridine: effects on time-to-failure and survival in patients with minimal residual ovarian cancer after second-look laparotomy-a randomized phase II study by the Southwest Oncology Group. Gynecol Oncol 1996;61:395-402.

46. Geng L, Huehls AM, Wagner JM, Huntoon CJ, Karnitz LM. Checkpoint Signaling, Base Excision Repair, and PARP Promote Survival of Colon Cancer Cells Treated with 5-Fluorodeoxyuridine but Not 5-Fluorouracil. PLoS One 2011;6:e28862.

47. Huehls AM, Wagner JM, Huntoon CJ, et al. Poly(ADP-ribose) polymerase inhibition synergizes with 5-fluorodeoxyuridine but not 5-fluorouracil in ovarian cancer cells. Cancer Res 2011;71:4944-54.

48. Zylberberg B, Ravina JH, Salat-Baroux J, Dormont D, Lipp B, Guillet JL. [Polychemotherapy of ovarian cancer via combined intravenous and intraperitoneal routes. Technic and preliminary results]. J Gynecol Obstet Biol Reprod (Paris) 1986;15:671-6.

49. Kirmani S, Braly PS, McClay EF, et al. A comparison of intravenous versus intraperitoneal chemotherapy for the initial treatment of ovarian cancer. Gynecologic Oncology 1994;54:338-44.

50. Polyzos A, Tsavaris N, Kosmas C, et al. A comparative study of intraperitoneal carboplatin versus intravenous carboplatin with intravenous cyclophosphamide in both arms as initial chemotherapy for stage III ovarian cancer. Oncology 1999;56:291-6.

51. Gadducci A, Carnino F, Chiara S, et al. Intraperitoneal versus intravenous cisplatin in combination with intravenous cyclophosphamide and epidoxorubicin in optimally cytoreduced advanced epithelial ovarian cancer: a randomised trial of the Gruppo Oncologico NordOvest. Gynecol Oncology 2000;76:157-62.

52. Yen MS, Juang CM, Lai CR, Chao GC, Ng HT, Yuan CC. Intraperitoneal cisplatin-based chemotherapy vs. intravenous cisplatin-based chemotherapy for stage III optimally cytoreduced epithelial ovarian cancer. Int J Gynaecol Obstet 2001;72:55-60. 
53. Jaaback K, Johnson N, Lawrie TA. Intraperitoneal chemotherapy for the initial management of primary epithelial ovarian cancer. Cochrane Database Syst Rev 2016;(1):CD005340.

54. The role of intraperitoneal chemotherapy in the first-line treatment of women with stage III epithelial ovarian cancer. Toronto (ON): Cancer Care Ontario 2012 Jun 25 [Education and Information 2011 Sep]. Program in Evidence-based Care Evidence-based Series No:421. 